\title{
Short-Term Daily Emergence of Adult Midges (Diptera: Chironomidae) from a Natural Lake and an Artificial Reservoir ${ }^{1}$
}

\author{
ARSHAD ALI, BRUCE H. STANLEY, ${ }^{2}$ AND STEPHEN R. STAFFORD \\ University of Florida, IFAS, Agricultural Research and Education Center, P.O. Box 909, Sanford, Florida 32771
}

Environ. Entomol. 12: 765-767 (1983)

\begin{abstract}
Daily emergence of adult Chironomidae in a lake and an artificial reservoir in Florida was sampled at 24-h intervals during spring and summer 1980 and summer 1981. Changes in water temperature during the sampling periods were recorded. Linear population trends of a species with time were examined by multiple linear regression. Temporal relationships of emergence periodicity within a species, between species, and between a catch of a species and daily water temperature were examined by autocorrelation and standard correlation analyses. Glyptotendipes paripes Edwards and Chironomus decorus Johannsen in the reservoir, and $G$. paripes and $C$. crassicaudatus Malloch in the lake, were quantitatively important and emerged on a daily basis at 18.5 to $30.0^{\circ} \mathrm{C}$ water temperatures. Trends of adult emergence of all species in relation to Julian day were inconsistent. Some significant autocorrelations and standard correlations existed, but all the correlation coefficient values were less than 0.66. From the daily emergence of the species studied, it can be suggested that their oviposition in central Florida lakes takes place almost on a daily basis at 18.0 to $30.0^{\circ} \mathrm{C}$ water temperatures, and several asynchronous generations of each species develop resulting in their asynchronous emergence.
\end{abstract}

In the last decade, the City of Sanford in central Florida has suffered increased annoyance and economic loss due to the frequent massive emergences of chironomid midges from adjacent Lake Monroe and an artificial reservoir. The nature of problems caused by adult midges were outlined by Ali (1980). A task force study ${ }^{3}$ indicated that Sanford suffers an annual loss of 3 to 4 million dollars due to chironomid-related problems, and at least 10 counties of Florida have similar midge problems. Reported here are the results of a study conducted to elucidate any specific patterns of midge emergence from the two habitats near Sanford during the periods of heavy emergence. Such basic understanding of the problem is essential to the formulation of control strategies.

\section{Materials and Methods}

The two sources of midges were described by Ali and Baggs (1982). Lake Monroe, supplied and emptied by the St. Johns River, has a surface area of ca. 4,000 ha, an average water depth of $2.5 \mathrm{~m}$, and a $20-\mathrm{km}$ shoreline. The reservoir, covering 450 ha and having a $6-\mathrm{km}$ shoreline, has an average water depth of $3 \mathrm{~m}$, and is also supplied by the river. The City of Sanford borders the southern 5- to $6-\mathrm{km}$ periphery of the lake.

Emergence of adult midges from the two habitats was sampled with submerged sheet metal cone emergence traps (Mulla et al. 1974). Each trap was $60 \mathrm{~cm}$ high and covered ca. $0.3 \mathrm{~m}^{2}$ of lake bottom area. To the conical end of the trap we attached a 1-liter Mason jar before lowering it onto the lake bottom. The emerging adults were captured in the jar.

'Fla. Agric. Exp. Stn. Journal Series No. 3915. Received for publication 21 June 1982; accepted 4 January 1983.

${ }^{2}$ Present address: New York State Agricultural Experiment Station, Dept. of Entomology, Cornell University, Geneva, NY 14456.

${ }^{3}$ Economic Impact Statement, 1977, Blind Mosquito (Midge) Task Force, Greater Sanford Chamber of Commerce, Seminole County, Fla. $4 \mathrm{pp}$.
In each habitat, three 4-ha square plots supporting midge larvae were marked off with buoys for sampling, and in each plot 10 traps were randomly placed. Adults emerging from the reservoir were sampled daily (24-h intervals) during spring (18 March to 6 May), and summer (15 July to 31 August) 1980 , and from the lake during summer (4 June to 10 July) 1980, and spring ( 30 March to 18 May) 1981. All collections were made during 8 to $11 \mathrm{a} . \mathrm{m}$. The precise method of collecting the adults was previously described (Ali and Mulla 1979). Throughout the sampling periods, the surface and bottom water temperatures in each habitat were measured at one location by a remote recording thermograph (Model T603, Weather Measure Corp., Sacramento, Calif.). Adult collections were brought to the laboratory for identification and counting.

Linear population trends with time were examined by using multiple linear regression by first fitting water temperature and the Julian day. The slope associated with Julian day was then tested for significance at the $95 \%$ confidence level by using a $t$ test. Temporal relationships between catches from 1 to 30 days apart were tested by autocorrelation analysis (Box and Jenkins 1976). To determine the degree to which water temperature affects daily emergence, the correlation coefficient between emergence and water temperature was calculated. Likewise, the correlation coefficient between species at a site was calculated to detect any trends among emergence patterns. All correlation and autocorrelation coefficients were tested for significant differences from zero at the $95 \%$ confidence level, using a $t$ test.

\section{Results and Discussion}

Among more than 20 species of midges taken from each habitat, only Glyptotendipes paripes Edwards and Chironomus decorus Johannsen in the reservoir, and $G$. paripes and Chironomus crassicaudatus Malloch in the lake, were quantitatively important. These three species pose pest problems in the Sanford area (Ali and Baggs 
Table 1. Summary of the trap catches ${ }^{a}$ for the predominant chironomid species and water temperature in two habitats near Sanford, Fla. (1980-1981)

\begin{tabular}{|c|c|c|c|c|c|c|c|c|c|c|}
\hline \multirow{2}{*}{ Site } & \multirow{2}{*}{ Sample } & \multicolumn{2}{|c|}{ Glypototendipes paripes } & \multicolumn{2}{|c|}{ Chironomus crassicaudatus } & \multicolumn{2}{|c|}{ Chironomus decorus } & \multicolumn{2}{|c|}{ Temp $\left({ }^{\circ} \mathrm{C}\right)$} & $\vec{n}$ \\
\hline & & $\overline{\mathrm{x}}^{h}$ & $\mathrm{SD}$ & $\overline{\mathrm{x}}^{b}$ & $\mathrm{SD}$ & $\overline{\mathrm{x}}^{b}$ & $\mathrm{SD}$ & $\overline{\mathbf{x}}^{\mathrm{c}}$ & SD & \\
\hline \multirow[t]{2}{*}{ Artificial Reservoir } & Spring & 8.8 & 7.1 & - & - & 3.2 & 2.1 & 23.6 & 1.8 & 48 \\
\hline & Summer & 6.6 & 5.0 & - & - & 2.3 & 1.5 & 27.7 & 1.1 & 48 \\
\hline \multirow[t]{2}{*}{ Lake Monroe } & Spring & 1.0 & 1.1 & 1.0 & 1.1 & - & - & 21.3 & 1.6 & 50 \\
\hline & Summer & 0.6 & 0.8 & 0.6 & 0.7 & - & - & 27.7 & 1.1 & 37 \\
\hline
\end{tabular}

aIn every case, the distribution of trap catches tended to be skewed to the right (i.e., nonnormal).

${ }^{b}$ Overall mean number per trap (covering $0.3 \mathrm{~m}^{2}$ of lake bottom) per day.

'Overall daily mean water temperature.
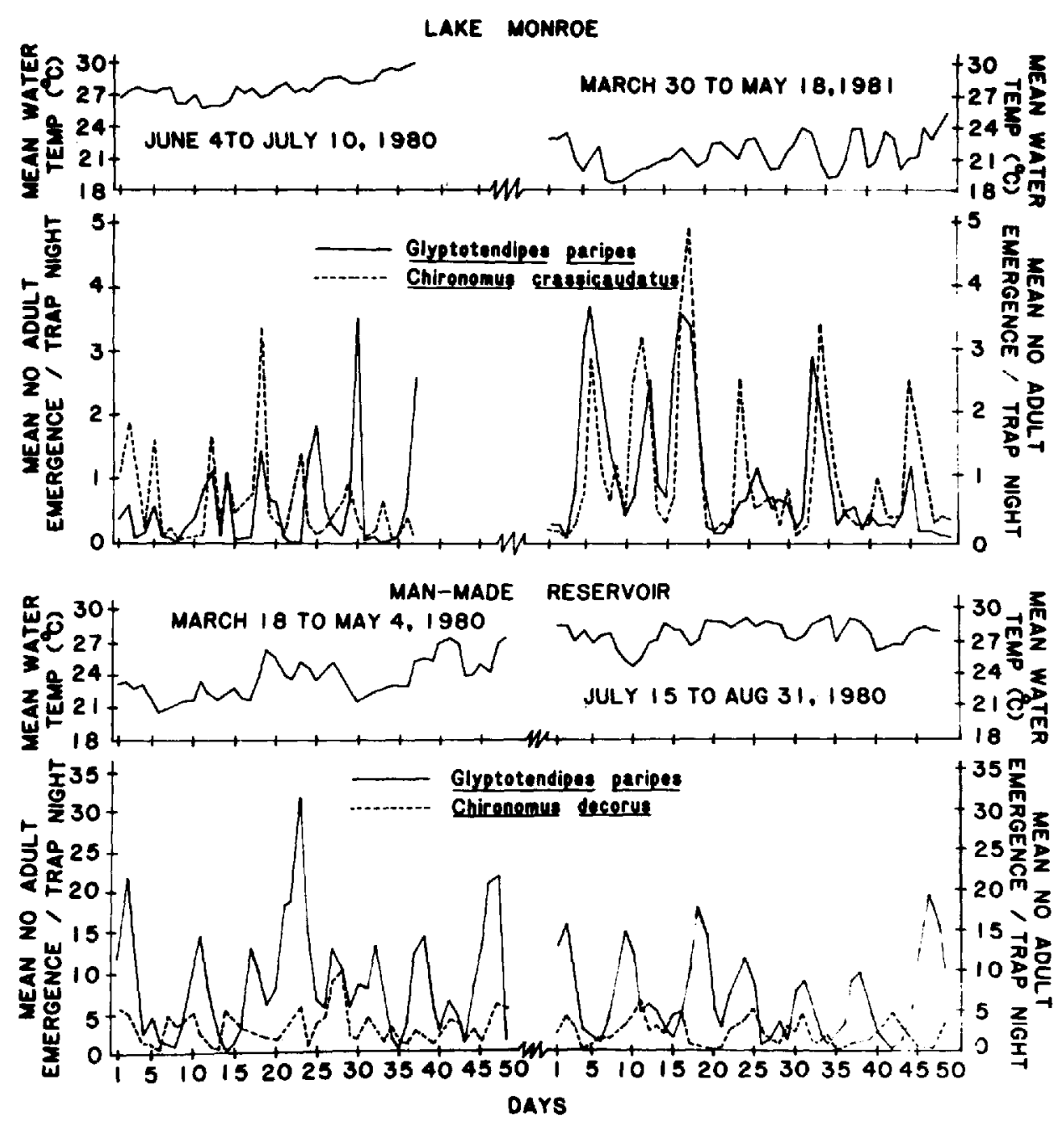

FIG. 1. Adult emergence trends of $G$. paripes, $C$. crassicaudatus, and $C$. decorus from Lake Monroe and an artificial reservoir, Sanford, Fla. (1980-1981).

1982). A summary of the trap catches of the predominant species in the two habitats is given in Table 1.

The daily catches of adult $G$. paripes and $C$. decorus in the reservoir during spring and summer 1980 and the changes in water temperature are shown in Fig. 1. It is evident that the water temperatures during the two sampling periods were sufficiently high $\left(20.6\right.$ to $\left.29.4^{\circ} \mathrm{C}\right)$ for $G$. paripes and $C$. decorus to emerge daily. The daily 
numbers of $C$. decorus during March through May and July through August fluctuated from 0.5 to 10.1 and 0.1 to 6.4 adults per trap night, respectively; adult $G$. paripes during the same time periods fluctuated from 0.2 to 32.1 and 0.4 to 19.2 per trap night. There was no significant increasing or decreasing emergence trend of either species with time in the reservoir. Chironomus decorus exhibited significant autocorrelations at 1,11 , and 20 days apart in spring and 1 day apart in summer. Significant autocorrelations were observed for $G$. paripes catches 1 day apart in the spring sample and 1, 3, and 4 days apart in the summer sample. The only significant correlation between emergence and water temperature was observed in the summer for $C$. decorus ( $r$ $=-0.57)$. No significant correlations were observed between catches of the two species.

$G$. paripes and $C$. crassicaudatus emerged on a daily basis from Lake Monroe when the water temperatures ranged from 18.5 to $30.0^{\circ} \mathrm{C}$. Daily mean numbers of the former species in summer (June through July) collections fluctuated from 0.03 to 3.6 , and in spring (March through May) from 0.08 to 3.7 adults per trap night; $C$. crassicaudatus fluctuated from 0.06 to 3.5 per trap night in summer and 0.08 to 4.9 per trap night in spring (Fig. 1). No significant trend in emergence of either species with time was noted except for $G$. paripes, showing a decreasing trend in the spring sample. Significant aulocorrelation only in spring collections was observed in G. paripes 1 day apart, and $C$. crassicaudatus catches 1,3 , and 6 days apart. No significant correlations with temperature were observed for either species. Glyptotendipes paripes catches were significantly correlated ( $r$ $=0.66$ ) with $C$. crassicaudatus catches in the spring sample.

The daily fluctuations of $G$. paripes and $C$. crassicaudatus apparently indicate a certain emergence rhythm with some day interval between peaks of emergence (Fig. 1), but the statistical analysis of the data revealed no consistent emergence trends related with Julian day of between days. The only consistent autocorrelation observed between catches was in catches 1 day apart. There were other significant autocorrelations, but in every case, the correlation coefficient value was $<0.66$. Similarly, no strong and consistent correlations of catches of a species with temperature, or between species in a babitat were observed. This study indicates that the best theoretical model for the adult emergence dynamics over a short time for the species studied is a mean with a random variation. The catch distributions tended to be skewed to the right in every case and could be reason- ably described by using the log-normal distribution.

There are no previously available quantitative data on the daily emergence of chironomids from subtropical regions to compare the results of the present study, although a number of studies on temporal variations in the seasonal emergence of Chironomidae of temperate and arctic regions have been reported (e.g., Butler 1980 , Mundie 1957, Danks and Oliver 1972, and others). Also, most of the species involved in these studies have much longer life cycles (several months) compared with the species studied presently; $G$. paripes and $C$. crassicaudatus in subtropical Florida complete their life cycles within 15 to 19 days at 27.0 to $31.0^{\circ} \mathrm{C}$ (Cowell and Vodopich 1981).

The daily emergence phenomenon of $G$. paripes, $C$. crassicaudatus, and $C$. decorus at water temperature ranges of 18.5 to $30.0^{\circ} \mathrm{C}$ suggests that oviposition of these species takes place on a daily basis at least during the spring, summer, and autumn seasons when the water temperatures in lakes of central Florida remain above $18.0^{\circ} \mathrm{C}$. During this period, several asynchronous generations of each species develop and result in their asynchronous emergence.

\section{REFERENCES CITED}

Ali, A. 1980. Nuisance chironomids and their control: a review. Bull. Entomol. Soc. Am. 26: 3-16.

Ali, A., and R. D. Baggs. 1982. Seasonal changes of chironamid populations in a shallow natural lake and in a manmade water cooling reservoir in central Florida. Mosq. News 42: 76-85.

Ali, A., and M. S. Mulla. 1979. Diel periodicity of eclosion of adult chironomid midges in a residential-recreational lake. Ibid. 39: 360-364.

Box, G. E. P., and G. M. Jenkins. 1976. Time series analysis: forecasting and control, Revised ed. Holden-Day, San Francisco. $575 \mathrm{pp}$.

Butler, M. G. 1980. Emergence phenologies of some arctic Alaskan Chironomidae, pp. 307-314. In D. A. Murray [ed], Chironomidae-ecology, systematics, cytology, and physiology, Pergamon Press, Oxford.

Cowell, B. C., and D. S. Vodopich. 1981. Distribution and seasonal abundance of benthic macro-invertebrates in a subtropical Florida lake. Hydrobiologia 78:97-105.

Danks, H. V., and D. R. Oliver. 1972. Seasonal emergence of some high arctic Chironomidae (Diptera). Can. Entomol. 104: 66l-686.

Mulla, M. S., R. L. Norland, T. Ikeshoji, and W. L. Kramer. 1974. Insect growth regulators for the control of aquatic midges. J. Econ. Entomol. 67: 165-170.

Mundie, J. H. 1957. The ecology of Chironomidae in storage reservoirs. Trans. R. Entomol. Soc. London 109: 149-232. 